\title{
OS EFEITOS DE GRANDES EMPREENDIMENTOS INDUSTRIAIS E PETROLÍFEROS EM CIDADES DO INTERIOR DO ESPÍRITO SANTO
}

\author{
Leandro de Souza Lino ${ }^{1}$
}

Resumo: Este trabalho avalia os efeitos de grandes empreendimentos industriais e petrolíferos, sobre cidades localizadas no interior do Espírito Santo, que se destacam por terem os maiores PIBs per capitas da região, em 2015. Entre esses municípios, estão Anchieta e Aracruz, que receberam grandes indústrias entre os anos de $1960 \mathrm{e}$ 1970, e Itapemirim, Marataízes e Presidente Kennedy, que vem se destacando na produção de petróleo desde a descoberta do Pré-sal, em 2007. Este trabalho aborda, tanto os aspectos históricos desses empreendimentos, como as características sociais, econômicas e urbanísticas dessas cidades. Através desta análise, constatase que a industrialização influenciou no crescimento populacional e, de certo modo, na urbanização de Anchieta e Aracruz, apesar de não ter sido em sua plenitude. Entretanto, nos demais, por terem recebido investimentos em petróleo em um período mais recente, ainda não se constata mudanças na estrutura de suas cidades.

Palavras-chave: Indústria; Petróleo; PIB per capita; Cidades; Desenvolvimento.

\section{THE EFFECTS OF LARGE INDUSTRIAL AND PETROLEUM ENTERPRISES IN CITIES INSIDE THE ESPÍRITO SANTO}

\begin{abstract}
This work assesses the effects of large industrial and oil projects on cities located in the interior of Espírito Santo, which stand out for having the highest GDPs per capita in the region, in 2015. Among these municipalities are Anchieta and Aracruz, which received large industries between the 1960s and 1970s, and Itapemirim, Marataízes and Presidente Kennedy, which has stood out in oil production since the discovery of the Pre-salt in 2007. This work it addresses both the historical aspects of these developments, as well as the social, economic and urban characteristics of these cities. Through this analysis, it appears that industrialization influenced the population growth and, in a way, the urbanization of Anchieta and Aracruz, despite not having been in its fullness. However, in the others, because they received investments in oil in a more recent period, there are still no changes in the structure of their cities.
\end{abstract}

Keywords: Industry; Petroleum; GDP per capita; Cities; Development.

\footnotetext{
${ }^{1}$ Possui graduação em Ciências Econômicas pela Universidade Federal do Espírito Santo (UFES). Mestre em Ciências (Economia Aplicada) pela Universidade de São Paulo. É doutor em Planejamento Urbano e Regional pela USP. Atualmente é professor efetivo da UNICAPE/União Capixaba de Ensino. E-mail: 1slino@gmail.com
} 


\section{INTRODUÇÃO}

O estado do Espírito Santo caracteriza-se por ter uma população e uma economia muito concentradas nos municípios da Região Metropolitana da Grande Vitória (RMGV). Esta região - constituída por Cariacica, Fundão, Guarapari, Serra, Viana, Vila Velha e Vitória -, apesar de ocupar 5,1\% do território estadual, detém quase metade da população $(48,0 \%$, conforme dados do Instituto Brasileiro de Geografia e Estatística - IBGE, 2010) e do PIB (53,4\%, Instituto Jones dos Santos Neves - IJSN, 2015) do Espírito Santo.

Além disso, destacam-se as características de alguns municípios do interior do Estado ${ }^{2}$, sobre o PIB per capita. É que entre os seis maiores resultados do Espírito Santo, em 2015 (conforme IJSN), cinco estão no interior (Presidente Kennedy, Itapemirim, Anchieta, Marataízes e Aracruz), e apenas um na RMGV (Vitória). Como o desempenho desses cinco município estão associados a história recente do Estado e possuem características distintas, este trabalho visa tratar sobre os motivos que levaram a tal situação, além de seus efeitos sobre suas dinâmicas sociais, econômicas e urbanas.

Os fatores históricos associados aos cinco municípios em questão, devem-se porque, dois receberam grandes empreendimentos industriais, em fins dos anos 1960 e 1970 (Aracruz, com a Aracruz Florestal - atual Suzano, em 1967; e, Anchieta, com a Samarco Mineração, em 1977) (ROCHA; MORANDI, 2012), e os demais, tem se destacado na produção de petróleo, em um período mais recente (BARROS, 2017).

Sobre os investimentos realizados em fins dos anos 1960 e 1970, ressalta-se que eles estão associados as mudanças ocorridas na economia estadual neste período. É que o Espírito Santo tinha uma economia agrícola, muito dependente do café até a década de 1960. Porém, com a crise na atividade, o governo federal adotou uma política de incentivo à erradicação dos cafezais, gerando um forte desempregado no campo e fazendo com que muitos migrassem para as cidades, especialmente a RMGV, que naquele momento, não possuíam estrutura para receber esse contingente (ROCHA; MORANDI, 2012).

A crise fortaleceu os interesses por implantar ações visando mudanças na economia local, como ocorreu em outros estados (PEREIRA, 1997). E, a partir dos anos 1970 "[...] intensificaram-se os esforços para atrair grandes capitais nacionais e estrangeiros [...], para o que se convencionou chamar de Grandes Projetos Industriais" (RIBEIRO, 2010, p. 30). Estes investimentos (privados e estatais), foram decididos durante o "milagre econômico" e iniciados após a crise de 1973, quando o governo federal implantou o II Plano Nacional de Desenvolvimento (II PND) (ROCHA; MORANDI, 2012, p. 136).

$\mathrm{Na}$ ocasião, o grande capital, aproveitando-se das condições favoráveis do Espírito Santo, como a localização e a "[...] existência de infraestrutura de transportes, de comunicações e energia elétrica; sistema de incentivos fiscais e de financiamento; estrutura econômica razoavelmente desenvolvida, etc [...]", optaram por implantar diversos projetos no Estado, apoiados pelo governo estadual (ROCHA; MORANDI, 2012, p. 136).

Além da Aracruz Celulose (1967) e da Samarco (1977), a partir de 1969, houve a ampliação da Vale no Espírito Santo - antiga Companhia Vale do Rio Doce (CVRD) -, bem como a implantação de outros, como a ArcelorMittal Tubarão, antiga

\footnotetext{
${ }^{2}$ Conforme a Lei Estadual $n^{\circ}$ 9.768, de 28 de dezembro de 2011, os 78 municípios do Espírito Santo estão divididos em 10 microrregiões, sendo uma, a RMGV (ESPÍRITO SANTO, 2011).
} 
Companhia Siderúrgica de Tubarão (CST), ambas na RMGV (ROCHA; MORANDI, 2012).

Destacam-se ainda as atividades da Petrobras no Espírito Santo, iniciadas em 1957, mas tendo como marco, a descoberta do primeiro campo de petróleo, em 1969. Porém, seu grande impulso no Estado ocorreu com as descobertas de petróleo na camada do Pré-sal (ROCHA; MORANDI, 2012, p. 39), principalmente a partir de 2007.

Assim, sobre os cinco municípios, nota-se que os investimentos realizados em Aracruz e Anchieta, nas décadas de 1960 e 1970, possibilitaram meios para que as cidades tivessem melhores características urbanísticas, caso seu desempenho econômico fosse convertido em benefícios as cidades. E, esta oportunidade surge novamente para os municípios com exploração de petróleo e gás natural, embora este tenha ganhado destaque apenas em um período mais recente, com a exploração do Pré-sal.

Desta forma, este trabalho pretende abordar os efeitos dos grandes empreendimentos industriais e petrolíferos nos municípios de Anchieta, Aracruz, Itapemirim, Marataízes e Presidente Kennedy, sobre suas áreas urbanas. Para tanto, inicialmente serão tratadas sobre a história e as características produtivas das empresas que atuam nestes locais e, em sequência, se terá uma análise conjuntural acerca destes empreendimentos e suas relações com as cidades objeto do referido estudo.

\section{OS EFEITOS DOS GRANDES EMPREENDIMENTOS NOS MUNICÍPIOS DO INTERIOR CAPIXABA}

\section{OS GRANDES EMPREENDIMENTOS}

Um dos primeiros grandes empreendimentos implantados nos cinco municípios, foi a Aracruz Celulose, em Aracruz. Esta empresa é resultado da captação de recursos estatais e privados (nacionais e estrangeiros), entre os anos 1960 e 1970, e teve o início de suas atividades, com plantios de eucalipto, em 1967 (ROCHA; MORANDI, 2012). Em 1978, teve-se a inauguração da planta industrial em Aracruz, para produção de celulose. Na ocasião, este investimento compreendia floresta, fábrica, terminal marítimo e infraestrutura, tendo um orçamento de US\$560 milhões e gerou 5.300 empregos diretos (BITTENCOURT, 1987, p. 233). Em 1985, foi inaugurado o Portocel, que se refere a uma estrutura portuária voltada para 0 embarque de celulose. Em 2009, a Votorantim Celulose e Papel (VCP) incorpora a Aracruz Celulose, iniciando a formação de uma nova empresa, a Fibria (FIBRIA, 2017), e sua sede administrativa deixa de ser no município de Aracruz. Já em 2019, ocorre a fusão da Fibria com a Suzano Papel e Celulose, dando origem a Suzano S.A. (SUZANO, 2021).

O segundo grande empreendimento foi a Samarco Mineração, localizado em Anchieta, e também é resultado da captação de recursos externos na década de 1970. A empresa, inaugurada em 1977, teve inicialmente como acionistas as americanas Samitri e Marcona Internacional, cujo investimento foi de US\$593 milhões. O empreendimento era constituído por mineroduto (entre Ouro Preto-MG e AnchietaES), Usina de Pelotização de minério de ferro e Porto. Em Anchieta, em 1979, a Usina e o Porto de embarque da empresa empregavam cerca de 450 trabalhadores (BITTENCOURT, 1987, p. 223). Atualmente a empresa é controlada pelas acionistas Vale e pela anglo-australiana BHP Billiton Brasil. A empresa também passou por algumas expansões recentemente, com a inauguração de outras três usinas de 
pelotização (em 1997, 2008 e 2014) (INSTITUTO ESTADUAL DE MEIO AMBIENTE E RECURSOS HÍDRICOS - IEMA, 2009; SAMARCO, 2014). Destaca-se que a construção da última usina teve início em 2011 e fim em 2013, com um investimento de $\mathrm{R} \$ 2,5$ bilhões, e uma capacidade de gerar 4.300 empregos na construção e 265 empregos na operação (FOLHA VITORIA, 2010). Entretanto, cabe destacar que diante do acidente da mina de rejeitos da empresa, localizada em Mariana-MG, a empresa teve suas atividades suspensas entre fins dos anos de 2015 e 2020 (GONTIJO; PIMENTEL, 2020).

Como já indicado, estes empreendimentos foram resultados das intervenções estatais e da captação de recursos nacionais e estrangeiros, para implantação de grandes projetos industriais no Espírito Santo (assim como ocorreu em outras regiões do país, durante o II PND). Sobre os investimentos do II PND, como muitos foram acompanhados por uma expansão na infraestrutura (viária, energética e de comunicações) pelo interior do país, esta situação possibilitou a transformação das antigas "metrópoles industriais", em "centros decisórios e administrativos". Tal fato ocorreu por conta da presença de grandes conglomerados financeiros e de corporações nas grandes cidades brasileiras, o que acabou por reforçar a sua centralidade metropolitana (NOBRE, 2001, p. 20). Sobre esta questão, embora as quatro maiores cidades do Estado atualmente (Vitória, Cariacica, Serra e Vila Velha), não tivessem um grande contingente no período da implantação dos projetos em Aracruz (1967) e em Anchieta (1977), quando se compara a realidade nacional, a sua participação na população total do Estado nos anos que se sucederam é significativa (passando de 13,2\%, em 1960, para 42,7\%, em 2010) (IBGE, 1940-2010) 3 .

Ainda sobre os empreendimentos citados, tem-se um ponto em comum, que é o de não ter suas sedes administrativas nos municípios indicados atualmente. Sobre este fato, Ferreira (2007, p. 08-09) afirma que, no cenário atual, "as empresas, ao se espalharem pelo mundo, não abrem mão de centralizar o comando e o capital em suas sedes. Na prática, a estratégia foi promover a divisão internacional do trabalho", para otimizar a lucratividade de um sistema em crise. Assim, "busca-se em cada país o que ele pode oferecer de mais vantajoso, mão-de-obra barata, ausência de restrições ambientais e/ou trabalhistas, proximidade da matéria-prima", entre outras (FERREIRA, 2007, p. 08-09). Destaca-se que alguns destes fatores podem ter contribuído para a implantação destes empreendimentos durante o período militar (1964-1985), além da própria proximidade com a matéria-prima.

Também sobre esta questão, vale citar o caso da Samarco que, diante dos passivos ambientais gerados por ela e por outras empresas localizadas na RMGV (Vale e ArcelorMittal), principalmente sobre poluição do ar e dos recursos hídricos, além dos impactos socioambientais, acabaram gerando a abertura da Comissão Parlamentar de Inquérito (CPI) do Pó Preto, em 2015. Os resultados da CPI indicaram que, mesmo com todas as evidências sobre os prejuízos socioambientais causados pelas empresas, em seu relatório, "[...] o documento expõe claramente as limitações que as mesmas e o poder público estão submetidos, tendo em vista a dependência econômica do Estado em relação a [suas] atividades" (FERREIRA, 2016, p. 236). Além disso, destaca-se que em novembro de 2015, com o rompimento da barragem de rejeitos de minério de Fundão, em Mariana (MG), a empresa interrompeu suas atividades até o ano de 2020 (GONTIJO; PIMENTEL, 2020).

\footnotetext{
${ }^{3}$ Destaca-se que estes quatro municípios também receberam grandes investimentos, tais como a ampliação da CVRD e a CST, como já mencionado. Além disso, conforme dados do IBGE, entre 1960 e 2010, os quatro ampliaram a sua participação no total da população capixaba, sendo iguais a 13,2\%, em 1960; 23,5\%, em 1970; 33,7\%, em 1980; 39,3\%, em 1991; 41,4\%, em 2000; e, 42,7\%, em 2010.
} 
Outro empreendimento de destaque e com atuação no Espírito Santo desde 1957 (apesar da descoberta do primeiro campo com produção comercial ter ocorrido em 1969), é a Petrobras. Todavia, o crescimento da atividade no Estado ocorreu com as descobertas de petróleo no Pré-sal (ROCHA; MORANDI, 2012), especialmente a partir de 2007. Tanto que, conforme dados da Agência Nacional do Petróleo, Gás Natural e Biocombustíveis (ANP, 2017), a produção de petróleo no Espírito Santo é a segunda maior do país (com 15,7\% do total do Brasi ${ }^{4}$ ) e a quarta maior em gás natural $\left(\right.$ com $10,3 \%$ da produção nacional ${ }^{5}$ ). Na Figura 1 , tem-se as atividades da Petrobras no Estado atualmente.

Figura 1. Atividades da Petrobras no Espírito Santo

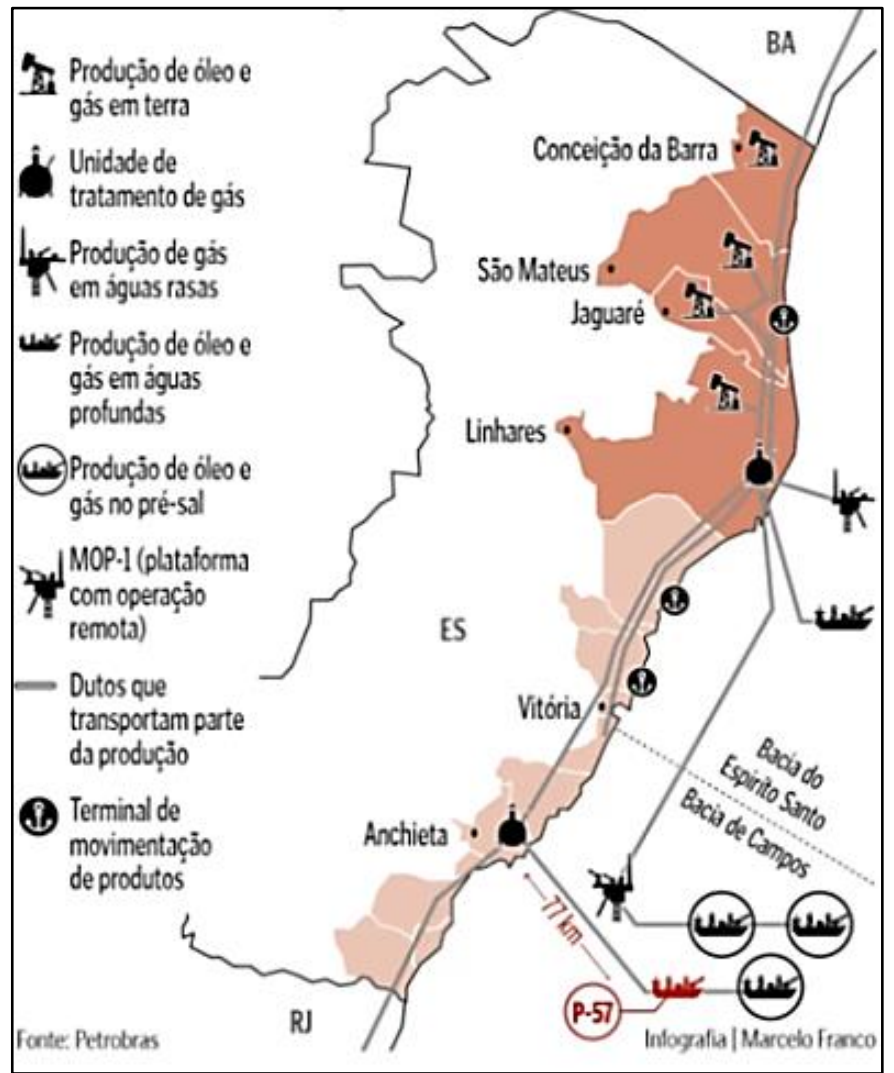

Fonte: Petrobras apud Rocetti; Seixas $(2017)^{6}$.

Segundo Vettorazzo (2017), a capital petrolífera do Espírito Santo, é Presidente Kennedy, que serve de base para exploração do Parque das Conchas e abriga os campos da Shell e da Petrobras.

Além disso, de acordo com dados da Aequus Consultoria (2017), entre os dez municípios capixabas que mais receberam royalties e participações especiais ${ }^{7}$, em

\footnotetext{
${ }^{4}$ Com uma produção de 144,2 milhões de barris, em 2016, o que corresponde a 15,7\% do total, ficando atrás apenas do Rio de Janeiro.

${ }^{5}$ Produzindo 3,9 milhões de $\mathrm{m}^{3}$, em 2016, o que representa 10,3\%, sendo os maiores produtores, Rio de Janeiro, São Paulo e Amazonas.

${ }^{6}$ A referida figura destaca a Plataforma "P-57", apenas por ser o objeto do referido artigo.

${ }^{7}$ Destaca-se que os royalties são constituídos como uma forma de compensação financeira, pela exploração de petróleo em seu território ou em plataformas continentais, sendo sua apuração, calculada a partir da cotação dos preços internacionais do petróleo e a quantidade extraída por campo de produção, pelas empresas concessionárias (AEQUUS CONSULTORIA, 2017).
} 
$2016^{8}$, quatro estão no litoral da microrregião "Litoral Sul" (ou seja, Presidente Kennedy, Itapemirim, Marataízes e Anchieta), sendo que apenas Piúma não estava na referida lista (ESPÍRITO SANTO, 2011). Com base nestas afirmações, nota-se a importância da produção de petróleo, na área que compreende a Bacia de Campos no Estado (Figura 01).

Ressalta-se ainda o surgimento de outros empreendimentos no Estado, devido a exploração de petróleo, sendo as implantações da Unidade de Tratamento de Gás (UTG Sul), em Anchieta, e do Terminal Aquaviário de Barra do Riacho (TABR), em Aracruz.

Sobre a UTG Sul, cujo empreendimento foi inaugurado em 2010, sua capacidade inicial era de processar 2,5 milhões de metros cúbicos de gás por dia (PETROBRAS, 2010). Já o TABR, teve um investimento de $R \$ 500$ milhões, com início de suas atividades em 2013, além de gerar 1.500 empregos durante as obras e 200 na operação (FOLHA VITORIA, 2010).

Além dos empreendimentos do próprio setor de petróleo e gás, destacam-se outros vinculados a atividade. Entre estes, o Estaleiro Jurong Aracruz (EJA), em Aracruz, voltado para fornecer sondas de perfuração e navios-plataforma para os campos do Pré-sal, no litoral brasileiro. Este empreendimento, cuja obra iniciou em 2011 , tem um investimento de $\mathrm{R} \$ 800$ milhões. Além disso, durante a sua construção, foram gerados 2.500 empregos diretos e indiretos, e na operação, 5.500. A entrega do primeiro navio construído no estaleiro, ocorreu em 2015 (ESTALEIRO JURONG ARACRUZ, 2017).

Através das Figuras 2 e 3, constata-se a localização dos empreendimentos existentes em Aracruz e Anchieta, respectivamente. Com base nestes mapas, observa-se a proximidade com áreas urbanizadas nos municípios, especialmente em Aracruz.

Figura 2 - Localização dos empreendimentos instalados em Aracruz

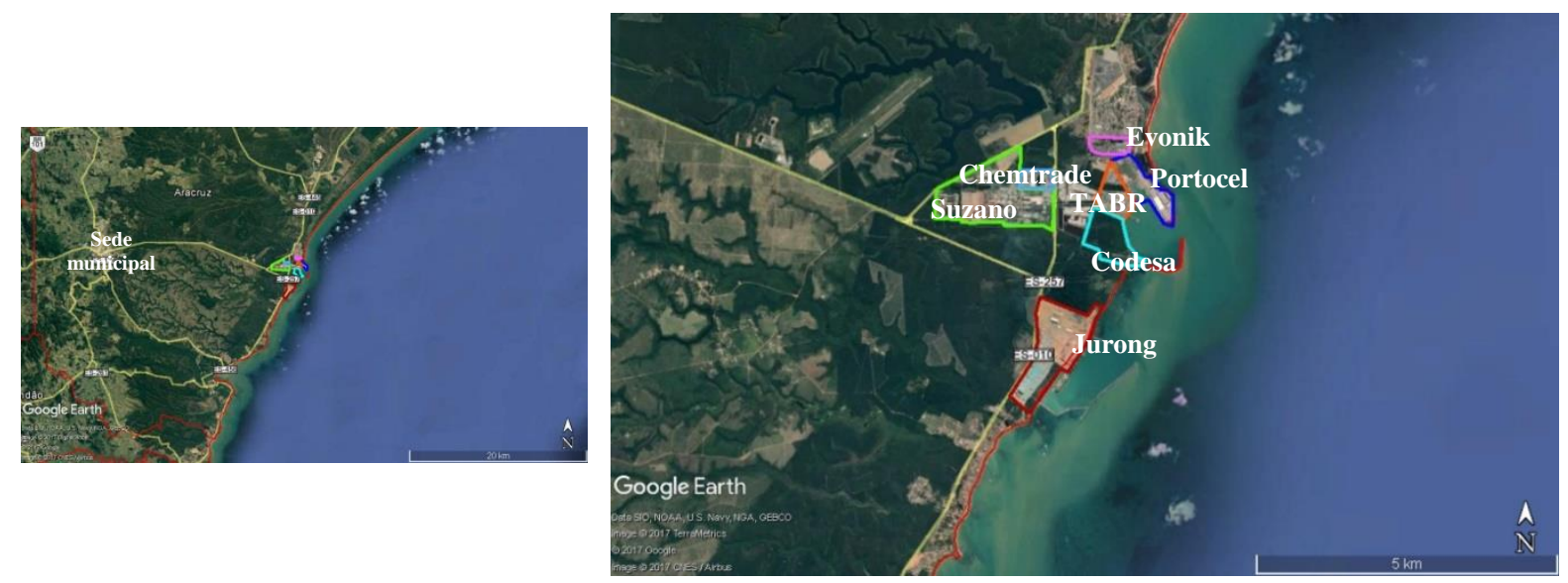

Fonte: Agência Nacional de Transportes Aquaviários - ANTAQ (2017). Elaborado pelo autor, 2021

Entre os empreendimentos citados na figura, os únicos que não foram mencionados no texto foram a Evonik Degussa (empresa alemã, que atua com especialidades químicas) ${ }^{9}$; a Chemtrade (empresa canadense, que produz cloreto de

\footnotetext{
${ }^{8}$ Sendo esta lista, composta por: Presidente Kennedy (R \$ 157,8 milhões), Itapemirim (R\$ 122,9 milhões), Linhares (R 71,6 milhões), Marataízes (R \$ 52,7 milhões), Aracruz (R \$ 21,5 milhões), São Mateus (R \$ 20,2 milhões), Serra (R \$ 18,2 milhões), Vitória (R\$ 15,4 milhões), Anchieta (R\$ 14,9 milhões) e Vila Velha (R\$ 12,2 milhões) (AEQUUS CONSULTORIA, 2017).

${ }^{9}$ EVONIK. Empresa. Disponível em: <http://central-south-america.evonik.com/>. Acesso em 02 jan. 2018.
} 
sódio $^{10}$ e a Codesa (Companhia Docas do Espírito Santo, que por sua vez, atualmente não possui movimentação de cargas - ANTAQ, 2017).

Figura 3 - Localização dos empreendimentos instalados em Anchieta

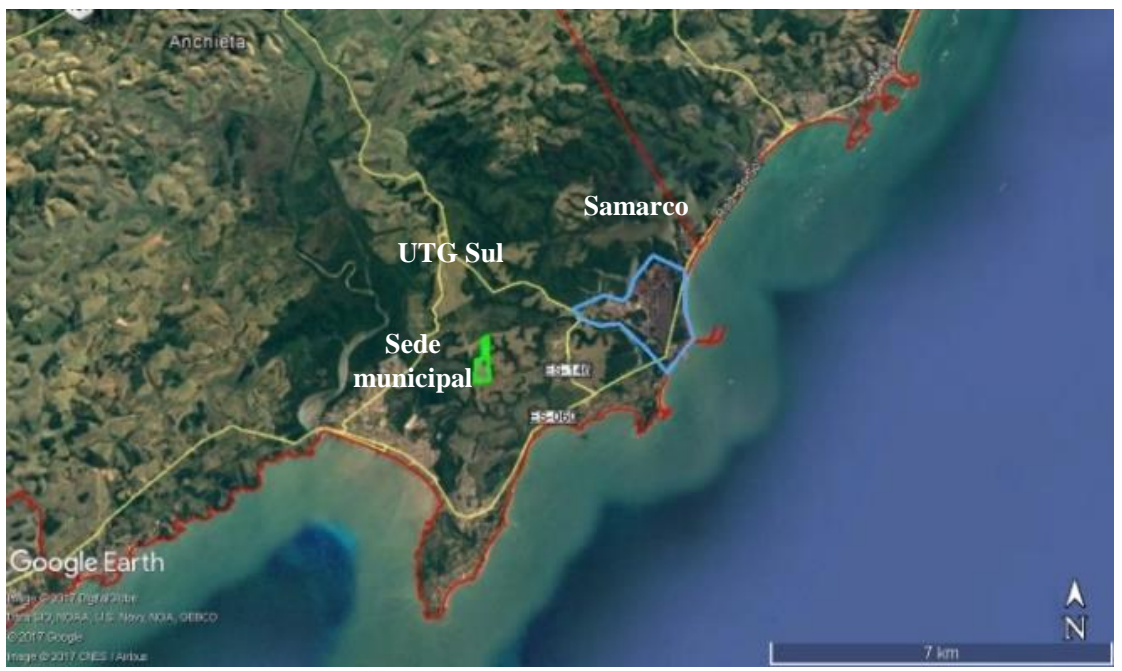

Fonte: Bitencourt (2013); Petrobras, 2010. Elaborado pelo autor, 2021

Através dos dados da Tabela 1, constata-se as motivações para a escolha dos cinco municípios, uma vez que, além dos fatores históricos e das características de suas atividades econômicas, os mesmos possuem os maiores PIBs per capitas do interior capixaba, no ano de 2015. Destaca-se que, entre 2002 e 2015, os três casos relacionados à produção de petróleo (Presidente Kennedy, Itapemirim e Marataízes), tiveram um aumento real em seus PIBs per capitas maior que $17 \%$ ao ano (enquanto o Estado, foi de 3,65\% ao ano). Já Anchieta e Aracruz, tiveram crescimentos menores que o total do Espírito Santo para o período, apesar das oscilações no PIB per capita anchietense (Gráfico 1).

Tabela 1. Os maiores PIBs per capitas entre os municípios do Estado, 2002-2015

\begin{tabular}{|c|c|c|c|c|}
\hline \multirow{2}{*}{ Ranking } & \multirow{2}{*}{ Municípios } & \multicolumn{2}{|c|}{ PIB per capita (em R\$)* } & \multirow{2}{*}{$\begin{array}{c}\text { TGCA 2002- } \\
2015^{11}\end{array}$} \\
\hline & & 2002 & 2015 & \\
\hline 1 & $\begin{array}{l}\text { Presidente } \\
\text { Kennedy }\end{array}$ & $39.926,13$ & $557.977,73$ & $22,49 \%$ \\
\hline 2 & Itapemirim & $12.200,90$ & $147.969,04$ & $21,16 \%$ \\
\hline 3 & Anchieta & $89.146,60$ & $108.601,91$ & $1,53 \%$ \\
\hline 4 & Marataízes & $8.487,07$ & $71.586,27$ & $17,82 \%$ \\
\hline 5 & Vitória & $59.349,50$ & $70.402,98$ & $1,32 \%$ \\
\hline 6 & Aracruz & $51.434,10$ & $60.774,27$ & $1,29 \%$ \\
\hline- & Espírito Santo & $20.886,60$ & $33.304,02$ & $3,65 \%$ \\
\hline
\end{tabular}

Fonte: IJSN (2002-2015).Nota: *A preços reais, corrigidos pelo IPCA, a preços médios de $2016^{12}$.

\footnotetext{
${ }^{10}$ CHEMTRADE LOGISTICS. Locations Overview. Disponível em: <http://www.chemtradelogistics.com/>. Acesso em 02 jan. 2018.

${ }^{11}$ A Taxa Geométrica de Crescimento Anual, é obtida pela fórmula: $T G C A=\left[\left(\sqrt[n]{\frac{P_{t+1}}{p_{t}}}\right)-1\right] x 100$; em que, $n$ é o número de anos no período; $P_{t}$ é o dado inicial, no começo do período; e, $P_{t+n}$ é o dado final, no fim do período.

${ }^{12}$ INSTITUTO BRASILEIRO DE GEOGRAFIA E ESTATÍSTICA - IBGE. Índice Nacional de Preços ao Consumidor Amplo - IPCA. 2013 a 2017. Disponível em: 〈www.ibge.gov.br〉. Acesso em 20 dez. 2017.
} 
Gráfico 1. PIB per capita dos municípios, em $\mathrm{R} \$$, 2002-2015*

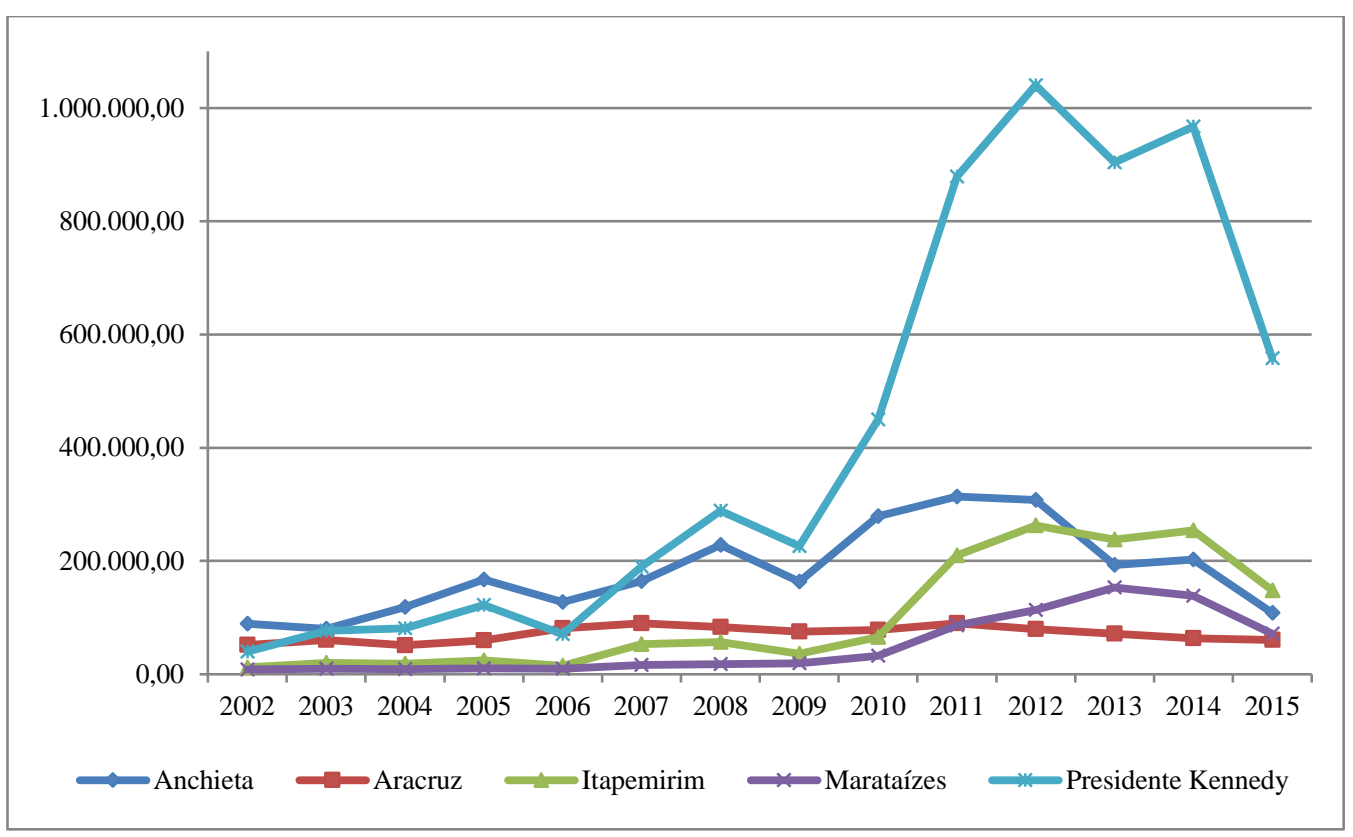

Fonte: IJSN (2002-2015).

Nota: *A preços reais, corrigidos pelo IPCA, a preços médios de 2016.

Em relação a importância dos grandes empreendimentos sobre as cidades, é importante citar um estudo de Arantes (2002). Nele, a autora, ao refletir sobre o questionamento sobre "quem de fato 'faz a cidade', [...] A resposta, ao menos a partir dos anos 1990, parece inequívoca: naturalmente, as grandes empresas, com as mediações de praxe, é claro" (ARANTES, 2002, p. 15). Apesar desta afirmação estar direcionada as empresas do setor imobiliário, a mesma também pode ser utilizada neste estudo, tendo em vista a potencial influência que estes empreendimentos possuem sobre suas respectivas economias, demostradas a partir das participações percentuais da indústria em seus $\mathrm{PIBs}^{13}$, e até mesmo, dos resultados da CPI do Pó Preto, como indicado por Ferreira (2016).

\section{OS EFEITOS DOS EMPREENDIMENTOS SOBRE AS CIDADES}

Entre os municípios de Anchieta, Aracruz e Presidente Kennedy, há um elemento comum em sua formação histórica, que é a origem por aldeias de índios catequizados por padres jesuítas ${ }^{14}$ (IBGE, 2017).

Em Itapemirim e Marataízes, dada a proximidade geográfica de suas sedes, suas histórias estão muito interligadas. O povoamento na região ocorreu pela existência de uma fazenda produtora de açúcar na foz do rio Itapemirim, em 1539 (IBGE, 2017). Os marcos históricos com a formação dos municípios estão no Quadro 1 , e suas respectivas localizações no território capixaba, na Figura 4.

\footnotetext{
${ }^{13} \mathrm{Em}$ 2015, as participações do setor industrial nos PIBs municipais foram iguais a 63,1\%, em Anchieta; 64,9\%, em Aracruz; 70,3\%, em Itapemirim; 63,8\%, em Marataízes; e, 76,8\%, em Presidente Kennedy.

${ }^{14}$ Apesar da ocupação em Aracruz e Presidente Kennedy, não ter se iniciado em suas sedes. Em Aracruz, a sua origem ocorreu no distrito de Santa Cruz, enquanto em Presidente Kennedy, na foz do rio Itabapoana, distante cerca de $20 \mathrm{~km}$ de sua atual sede.
} 
Quadro 1 - Informações sobre a emancipação dos municípios e suas atuais divisões administrativas (em distritos)

\begin{tabular}{|l|r|r|l|l|}
\hline Municípios & Ano de criação & $\begin{array}{c}\text { Ano de } \\
\text { instalação }\end{array}$ & Proveniência & \multicolumn{1}{|c|}{ Divisão administrativa } \\
\hline Anchieta & 1759 & 1887 & & $\begin{array}{l}\text { Sede, Alto Pongal e } \\
\text { Jabaquara }\end{array}$ \\
\hline Aracruz & 1556 & 1891 & & $\begin{array}{l}\text { Aracruz, Guaraná, } \\
\text { Jacupemba, Riacho e Santa } \\
\text { Cruz }\end{array}$ \\
\hline Itapemirim* & 1815 & 1939 & $\begin{array}{l}\text { Sede, Itaipava, Itapecoá, } \\
\text { Piabanha do Norte e Rio } \\
\text { Muqui }\end{array}$ \\
\hline $\begin{array}{l}\text { Marataízes* } \\
\text { Presidente } \\
\text { Kennedy* }\end{array}$ & 1992 & 1997 & Itapemirim & Sede e Barra do Itapemirim \\
\hline
\end{tabular}

Fonte: IBGE (2017).

Nota: *Informações utilizadas para estimar a população dos municípios, de maneira proporcional, em período anterior a sua emancipação.

Figura 4. Localização dos municípios estudados no estado do Espírito Santo

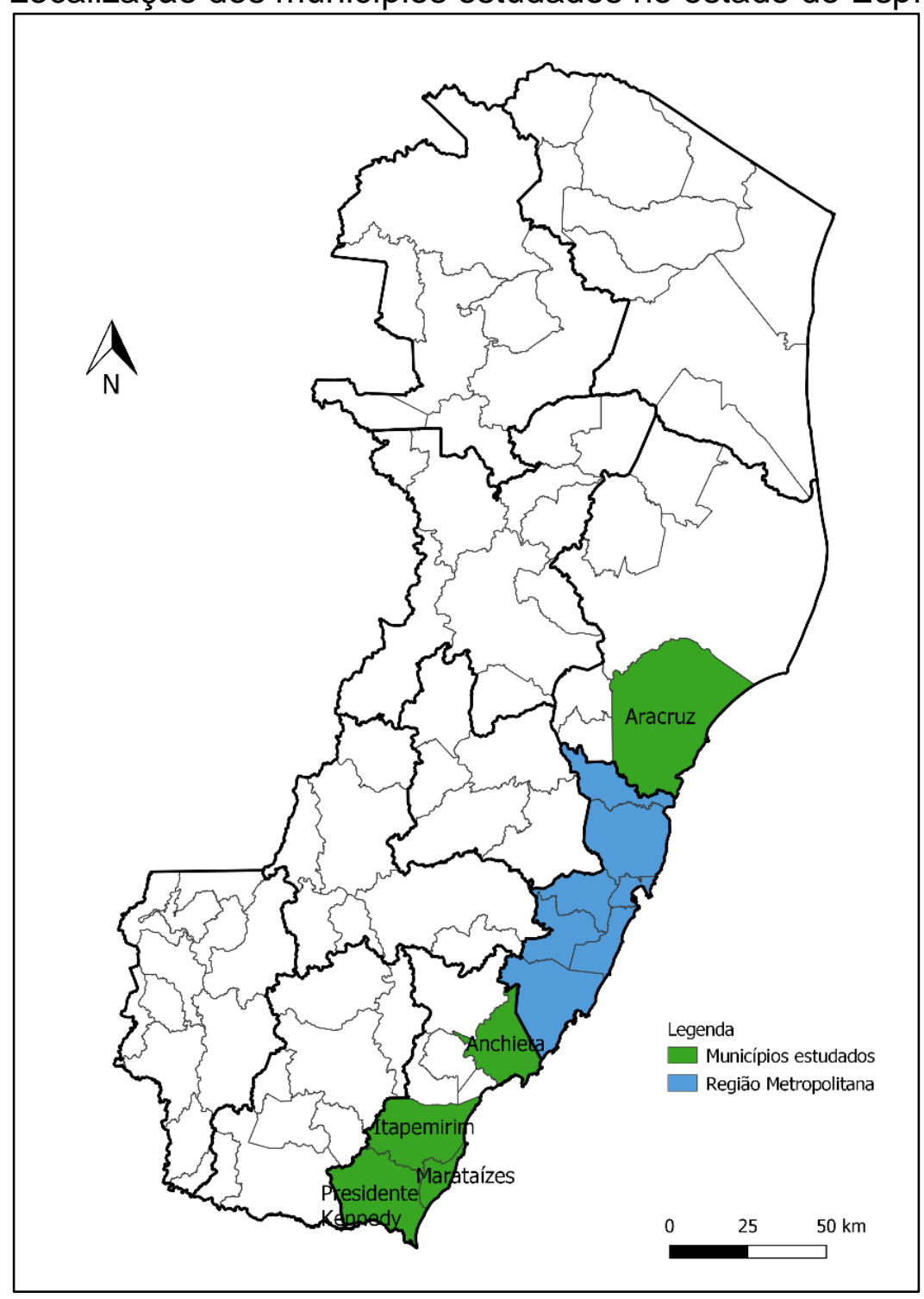

Fonte: Elaborado pelo autor, 2021 
Para avaliar o tamanho e o crescimento populacional nos cinco municípios, antes e após a implantação dos empreendimentos, tem-se os dados sobre a quantidade de habitantes, conforme Gráfico 2, e a Taxa Geométrica de Crescimento Anual (TGCA) entre cada um dos levantamentos censitários, entre 1940 e 2010, e as estimativas do IBGE, para 2016, de acordo com a Tabela 2.

Neste caso, em Anchieta, os dados dos Censos realizados antes e após a inauguração da Samarco, ocorrida em 1977, demonstram que o município possuía 11.361 habitantes, em 1970, e 11.413 pessoas, em 1980. Como se percebe, a implantação da Samarco (em 1977) influenciou pouco o seu tamanho populacional, em um primeiro momento. Porém, nos anos que se seguiram, após o Censo de 1980, Anchieta apresentou taxas de crescimento anual superiores às do Estado, e chegou em 2010, com 23.902 pessoas, ou seja, mais que o dobro de habitantes daquele ano $(1980)^{15}$.

Já Aracruz, nos levantamentos censitários anterior e posterior ao início dos plantios de eucalipto da Aracruz Celulose, em 1967, o município contava com 24.037 habitantes, em 1960, e 26.507 pessoas, em 1970. E, com as inaugurações da planta industrial da empresa, em 1978, a população municipal ampliou para 35.791 pessoas, em $1980^{16}$, enquanto que, com a da Portocel, em 1985, passou para 52.433 habitantes, em 1991. Destaca-se ainda que em todos os levantamentos censitários posteriores a 1970, Aracruz cresceu mais que o Estado, chegando ao último, em 2010, com 81.832 pessoas (ou seja, três vezes mais que o identificado em 1970).

Sobre Itapemirim, Marataízes e Presidente Kennedy, nota-se que apenas na década de 1960, eles tiveram crescimentos superiores ao registrado pelo total do Espírito Santo. Neste caso, vale lembrar a crise com a qual o Estado passava, tendo em vista a política de erradicação dos cafezais, como já demonstrado e indicado no estudo de Rocha e Morandi (2012). Todavia, em um período mais recente, mesmo com o desempenho da atividade petrolífera no litoral capixaba, especialmente a partir da divulgação do Pré-sal (em 2007 ${ }^{17}$ ), ainda não se nota nos levantamentos do IBGE, crescimentos em suas populações, que superem o verificado no Estado. E, mesmo nos resultados entre 2010 e as estimativas do instituto para 2016, não se tem indicativos de crescimento populacional que superem o desempenho destes municípios ao estadual, mesmo com as perspectivas de investimentos ${ }^{18}$ para os próximos anos na região ${ }^{19}$, especialmente Itapemirim ${ }^{20}$ e Presidente Kennedy ${ }^{21}$.

\footnotetext{
${ }^{15}$ Cabe destacar as alterações no número de habitantes nos municípios circunvizinhos à Anchieta, especialmente Guarapari, que passou de 24.105 pessoas, em 1970; para 105.286, em 2010. Porém, este debate não faz parte dos objetivos deste trabalho. ${ }^{16}$ Porém, um dos fatores que podem ter contribuído para Aracruz não ter um grande crescimento populacional, como verificado em outros municípios, está a sua proximidade com as grandes cidades da RMGV, já que, entre a planta industrial da Fibria e o bairro de Nova Almeida, em Serra, há uma distância de 36km, enquanto a distância da fábrica a sede municipal de Aracruz, é de $22 \mathrm{~km}$.

${ }^{17}$ LUNA, D; KHALIP, A. Petrobras descobre reserva gigante de petróleo; ações disparam. Reuters Brasil. 08 nov. 2007. Disponível em: <https://br.reuters.com/article/topNews/idBRN0820855620071108>. Acesso em 04 dez. 2017.

18 INSTITUTO JONES DOS SANTOS NEVES - IJSN. Investimentos Anunciados 2016-2021. 2017. Disponível em: <http://www.ijsn.es.gov.br/>. Acesso em 25 out. 2017.

${ }^{19}$ Para explorar petróleo nos campos do Litoral Sul do ES, nos municípios de Anchieta, Piúma, Itapemirim, Marataízes e Presidente Kennedy, estima-se um investimento total de R \$ 2.540,1 milhões, no período entre os anos de 2016 e 2021 (IJSN, 2017).

${ }^{20}$ Com o Itaoca Offshore, um terminal privativo para atender a indústria de petróleo e gás, estimado em R \$ 614,1 milhões (IJSN, 2017).

${ }^{21}$ Com o Porto Central, um porto-indústria para atender setores como petróleo e gás, minério, granito, agricultura, indústria automobilística, entre outros, estimado em R \$ 6.012,9 milhões (IJSN, 2017).
} 
Gráfico 5. População dos municípios, 1940-2016*

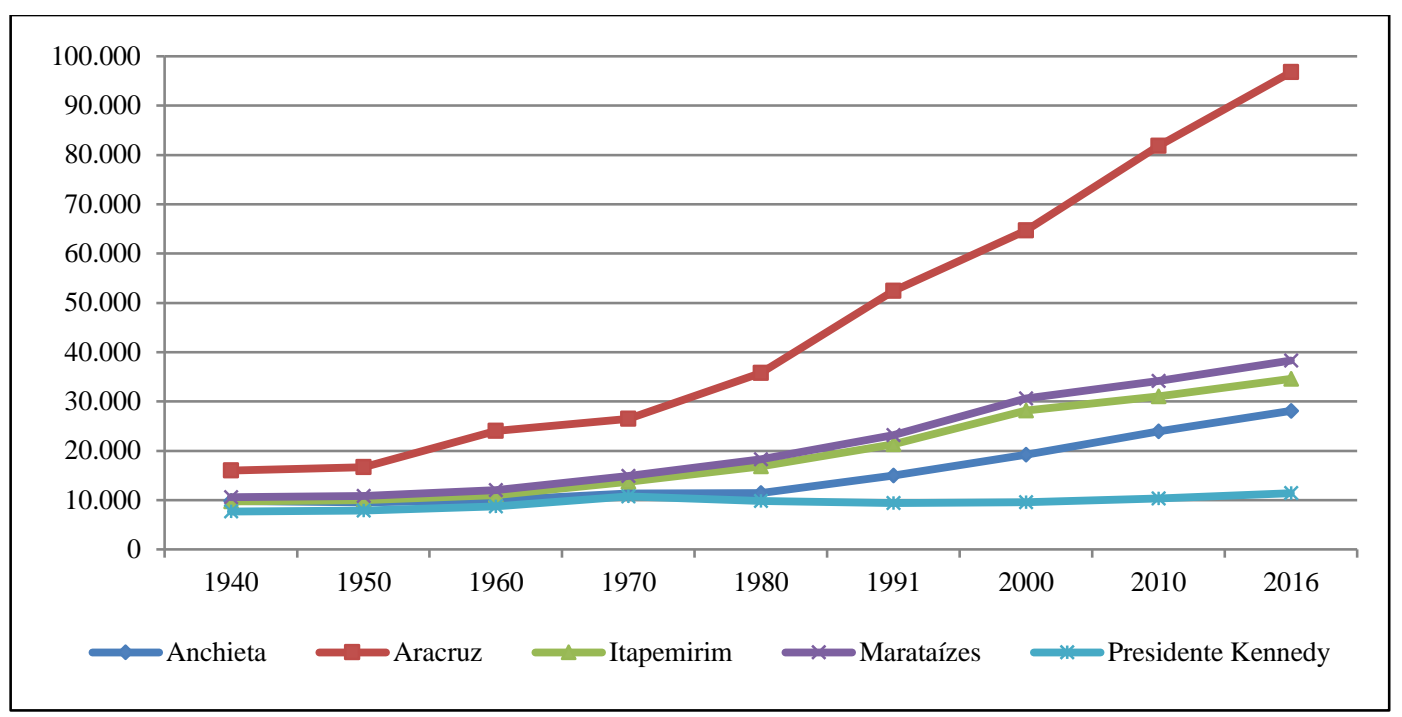

Fonte: IBGE (1940-2010); IBGE (2016).

Nota: *Os dados de Itapemirim, Marataízes e Presidente Kennedy anteriores a suas emancipações, foram estimados, conforme a proporcionalidade apresentada em seus primeiros levantamentos censitários.

Tabela 2. Taxa Geométrica de Crescimento Anual dos municípios, 1940-2016*

\begin{tabular}{|c|c|c|c|c|c|c|c|c|c|}
\hline M & $\begin{array}{l}\text { TGCA } \\
1940- \\
1950\end{array}$ & $\begin{array}{c}\text { TGCA } \\
1950- \\
1960\end{array}$ & $\begin{array}{c}\text { TGCA } \\
1960- \\
1970\end{array}$ & $\begin{array}{l}\text { TGCA } \\
1970- \\
1980\end{array}$ & $\begin{array}{c}\text { TGCA } \\
1980- \\
1991\end{array}$ & $\begin{array}{l}\text { TGCA } \\
1991- \\
2000\end{array}$ & $\begin{array}{l}\text { TGCA } \\
2000- \\
2010\end{array}$ & $\begin{array}{l}\text { TGCA } \\
2010- \\
2016\end{array}$ & $\begin{array}{l}\text { TGCA } \\
1940- \\
2016\end{array}$ \\
\hline nchieta & $-0,3 \%$ & $0,4 \%$ & $1,3 \%$ & $0,0 \%$ & $2,5 \%$ & $2,8 \%$ & $2,2 \%$ & $1,6 \%$ & $1,9 \%$ \\
\hline Aracruz & $0,4 \%$ & $3,7 \%$ & $1,0 \%$ & $3,0 \%$ & $3,5 \%$ & $2,4 \%$ & $2,4 \%$ & $1,7 \%$ & $3,3 \%$ \\
\hline Itapemirim & $0,3 \%$ & $1,0 \%$ & $2,2 \%$ & $2,1 \%$ & $2,2 \%$ & $3,1 \%$ & $1,0 \%$ & $1,1 \%$ & $2,3 \%$ \\
\hline Mara & $0,3 \%$ & $1,0 \%$ & $2,2 \%$ & $2,1 \%$ & $2,2 \%$ & $3,1 \%$ & $1,1 \%$ & $1,2 \%$ & $2,3 \%$ \\
\hline $\begin{array}{l}\text { Presidente } \\
\text { Kennedy }\end{array}$ & $0,3 \%$ & $1,0 \%$ & $2,2 \%$ & $-1,0 \%$ & $-0,3 \%$ & $0,1 \%$ & $0,8 \%$ & $1,0 \%$ & $0,7 \%$ \\
\hline $\begin{array}{l}\text { Espírito } \\
\text { Santo }\end{array}$ & $1,9 \%$ & $4,0 \%$ & $1,2 \%$ & $2,4 \%$ & $2,3 \%$ & $2,0 \%$ & $1,3 \%$ & $1,2 \%$ & $2,9 \%$ \\
\hline
\end{tabular}

Nota: * Os dados de Itapemirim, Marataízes e Presidente Kennedy anteriores a suas emancipações, foram estimados, conforme a proporcionalidade apresentada em seus primeiros levantamentos censitários.

Os dados a seguir, tratam sobre as cinco cidades e alguns indicadores sociais e urbanísticos. Sobre as cidades, conforme Ferreira (2005), tem-se que elas se caracterizam por ser um ambiente construído, ou seja, um espaço produzido e resultado do trabalho social. Em relação ao solo urbano, seu valor é determinado por sua localização, resultado do "trabalho social necessário para tornar o solo edificável (a infraestrutura urbana), as próprias construções que [existem], a facilidade de acessá-lo (sua 'acessibilidade') e, enfim, a demanda" (FERREIRA, 2005, p. 05-06).

No início do século XX, o Estado brasileiro teve um controle sobre a produção do espaço urbano, "às avessas", já que ele ocorreu para atender as elites, e manter as áreas de classe média em níveis aceitáveis, deixando o mercado imobiliário bastante livre para atuar (FERREIRA, 2005, p. 07-08). 
Porém, é com a industrialização que a diferenciação espacial pela localização e a intervenção estatal se destacam, já que ela é um "fenômeno essencialmente urbano". Ou seja, a cidade se torna o lócus do próprio sistema de produção (FERREIRA, 2005).

Diante destas afirmações, têm-se que por serem municípios com menos de 100 mil habitantes e por não terem estudos que indiquem os preços dos imóveis, optouse por avaliar, além das características sobre o espaço construído (através da análise sobre os domicílios e seu entorno), o mercado de trabalho da construção civil nos últimos anos.

Já em relação aos efeitos da industrialização sobre as cidades, eles podem ser constatados por meio da taxa de urbanização, no Gráfico 3. Observa-se que todos tiveram um crescimento em suas taxas após os anos 1970, sendo o maior resultado em 2010, verificado em Aracruz. Além disso, este município, em conjunto com Anchieta, tiveram um crescimento acelerado em suas taxas de urbanização na década de 1970, lembrando que este foi o período da implantação de seus grandes projetos industriais.

Por outro lado, Presidente Kennedy, caracterizado por ser o que detém o maior PIB per capita do Estado, em 2015, além de ser o menos populoso (10.314 habitantes) entre os cinco, em 2010, também é o que possui a menor taxa de urbanização $(33,4 \%)$. Contudo, destaca-se que sua inserção na economia estadual ocorreu apenas recentemente de forma mais intensiva, a partir do aumento da exploração de petróleo em seu litoral.

Gráfico 6.Taxa de urbanização dos municípios, 1970-2010

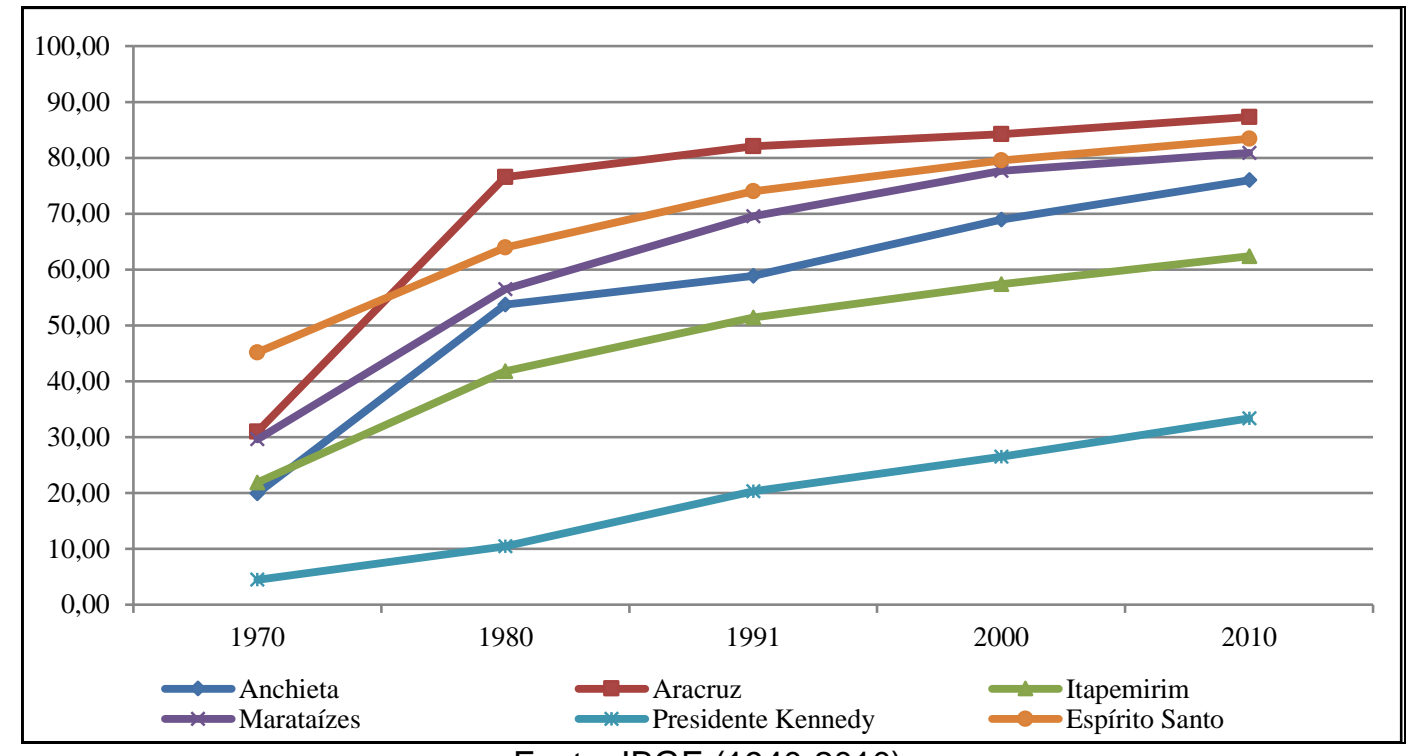

Fonte: IBGE (1940-2010).

Através da Tabela 3, é possível comparar o desempenho demográfico, econômico e social, dos cinco municípios, com os demais do Espírito Santo, por meio de dados sobre a população, o PIB e o PIB per capita, e o Índice de Desenvolvimento Humano (IDH), e suas respectivas indicações no ranking dos 78 municípios do Estado. Sobre os desempenhos dos municípios, percebe-se que nos casos de Itapemirim, Marataízes e Presidente Kennedy, apesar de eles terem praticamente mantido suas posições nos rankings sobre a população, entre 2000 e 2010, e de terem melhorado nos que tratam sobre seus indicadores econômicos (PIB e PIB per capita), 
os mesmos não foram acompanhados no social (IDH, apesar das melhorias notadas em seus resultados absolutos)

Tabela 3. Comparativo entre População (em número de habitantes), PIB (em milhões de $R \$$ ), PIB per capita (em mil de R\$) e IDH, nos anos de 2000 e 2010

\begin{tabular}{|c|c|c|c|c|c|c|c|c|c|c|c|}
\hline \multirow{2}{*}{ Indicador } & \multirow{2}{*}{ Opções } & \multicolumn{2}{|c|}{ Anchieta } & \multicolumn{2}{|c|}{ Aracruz } & \multicolumn{2}{|c|}{ Itapemirim } & \multicolumn{2}{|c|}{ Marataízes } & \multicolumn{2}{|c|}{$\begin{array}{c}\text { Presidente } \\
\text { Kennedy }\end{array}$} \\
\hline & & 2000 & 2010 & 2000 & 2010 & 2000 & 2010 & 2000 & 2010 & 2000 & 2010 \\
\hline \multirow{2}{*}{ População ${ }^{1}$} & Resultado & 19.176 & 23.902 & 64.637 & 81.832 & 28.121 & 30.988 & 30.603 & 34.140 & 9.555 & 10.314 \\
\hline & Ranking ES* & 35 & 35 & 10 & 10 & 20 & 20 & 17 & 17 & 66 & 67 \\
\hline \multirow{2}{*}{$\begin{array}{l}\text { PIB (em } \\
\text { bilhões de } R \$)^{2}\end{array}$} & Resultado & 2,00 & 6,67 & 3,31 & 6,39 & 0,40 & 2,02 & 0,30 & 1,12 & 0,40 & 4,64 \\
\hline & Ranking ES* & 8 & 5 & 5 & 6 & 19 & 11 & 28 & 15 & 20 & 9 \\
\hline \multirow{2}{*}{$\begin{array}{l}\text { PIB per capita } \\
(\text { em mil de } \mathrm{R} \$)^{2}\end{array}$} & Resultado & 104,18 & 279,31 & 51,17 & 78,17 & 14,32 & 65,34 & 9,71 & 32,88 & 41,56 & 449,63 \\
\hline & Ranking ES* & 1 & 2 & 3 & 4 & 24 & 5 & 59 & 10 & 4 & 1 \\
\hline \multirow{2}{*}{$\mathrm{IDH}^{3}$} & Resultado & 0,627 & 0,730 & 0,638 & 0,752 & 0,525 & 0,654 & 0,592 & 0,696 & 0,532 & 0,657 \\
\hline & Ranking ES* & 13 & 11 & 9 & 4 & 67 & 70 & 33 & 33 & 62 & 66 \\
\hline
\end{tabular}

Fonte: ' IBGE (2000-2010); ' 2 Instituto de Pesquisa Econômica Aplicada - IPEA (2000-2010) e IJSN (2002-2015); ${ }^{3}$ Programa das Nações Unidas para o Desenvolvimento - PNUD (2013).

Nota: *"Ranking ES" representa a posição dos municípios entre os 78 do Espírito Santo.

${ }^{2}$ Os dados do PIB de 2000 foram estimados através da inferência entre os resultados identificados no IJSN (2002-2015) e o IPEA (2000-2010). Cabe destacar que em 2002 e 2010, ocorreram mudanças nos cálculos do PIB e, por isso, não é possível fazer análises mais ampliadas, apesar das estimativas apresentadas neste caso, tendo como base, a série retropolada (IJSN, 2002-2015).

2PIB a preços reais, corrigidos pelo IPCA, a preços médios de 2016.

Já nos municípios de Anchieta e Aracruz, embora suas posições nos rankings estadual de suas populações tenham se mantido, seus desempenhos para o PIB, 0 PIB per capita e IDH foram diferentes. Isso porque, Anchieta melhorou nos rankings estaduais do PIB e do IDH, mas piorou no do PIB per capita. Enquanto Aracruz, piorou no PIB e no PIB per capita, mas melhorou no IDH.

Ainda sobre indicadores sociais, tem-se na Tabela 4, informações sobre o índice de Gini, entre 2000 e 2010. Destaca-se que todos reduziram seus resultados, entre os referidos anos, o que indica uma desconcentração de renda em suas populações. Além disso, todos os cinco municípios tiveram resultados inferiores aos do Estado, em 2010.

Sobre as características dos domicílios, tem-se que, apenas Marataízes teve um aumento nos valores para o "percentual de pessoas em domicílios com abastecimento de água e esgotamento sanitário inadequados", entre 2000 e 2010, passando de $0,61 \%$ para $1,35 \%$, respectivamente. Já os demais, todos melhoraram seus resultados neste período.

Enquanto Presidente Kennedy, mesmo com sua reduzida população, quando se comparado aos demais quatro municípios, e apesar de ter o maior PIB per capita do Estado, todos seus resultados sobre os domicílios, em 2010, foram inferiores ao estadual. 
Tabela 4. Alguns indicadores gerais do Atlas do Desenvolvimento Humano, dos municípios selecionados, 2000-2010

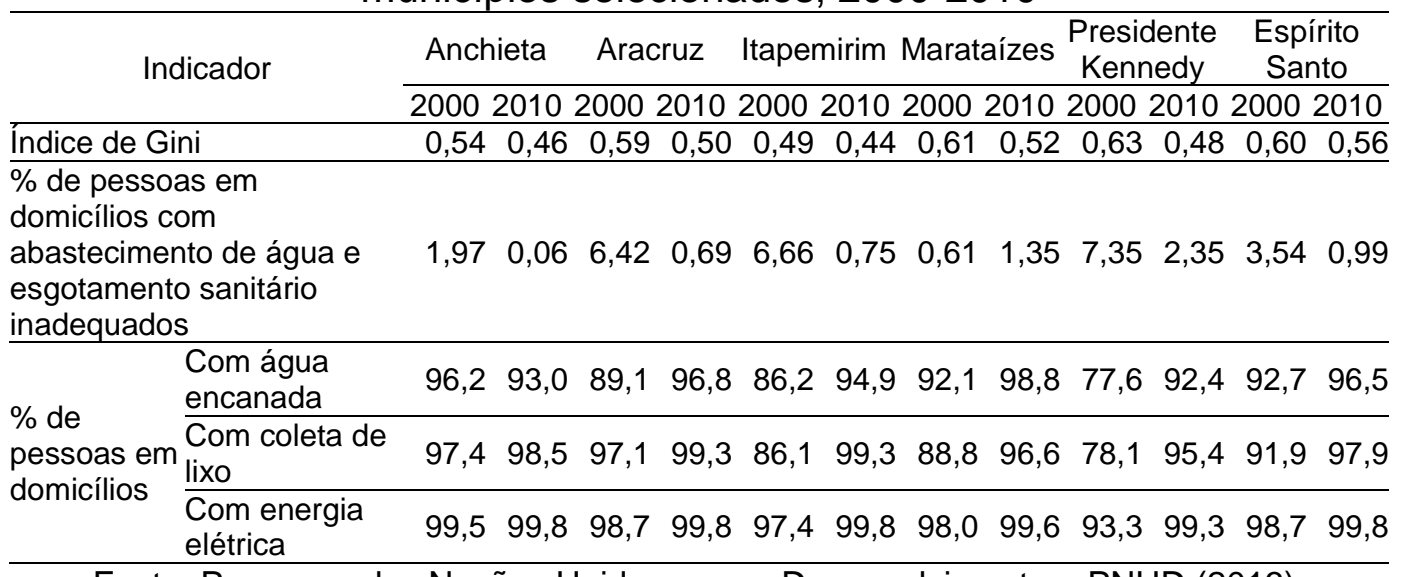

Fonte: Programa das Nações Unidas para o Desenvolvimento - PNUD (2013).

Nota: Ranking ES representa a posição dos municípios entre os 78 do Espírito Santo.

Por meio do Gráfico 4, tem-se as características gerais sobre o entorno dos domicílios localizados em áreas urbanas e com ordenamento regular, conforme a existência dos itens listados, em 2010. Observa-se que em todos os cinco municípios, o item "rampa para cadeirante" foi o que teve menores resultados.

Além disso, Itapemirim e Marataízes se destacaram por terem os piores resultados para "pavimentação" e "meio fio/guia" (Gráfico 4). Além disso, em conjunto com Presidente Kennedy, eles também tiveram os piores resultados para "calçada", e junto com Anchieta, para "bueiro/boca de lobo". Sobre Aracruz, destaca-se o fato de o município ter apresentado os maiores percentuais de domicílios com "esgoto a céu aberto" e "lixo acumulado nos logradouros", cujos valores superaram os $4 \%$.

Gráfico 7. Percentual das características no entorno dos domicílios localizados em áreas urbanas e com ordenamento regular, conforme a existência dos itens listados, em 2010

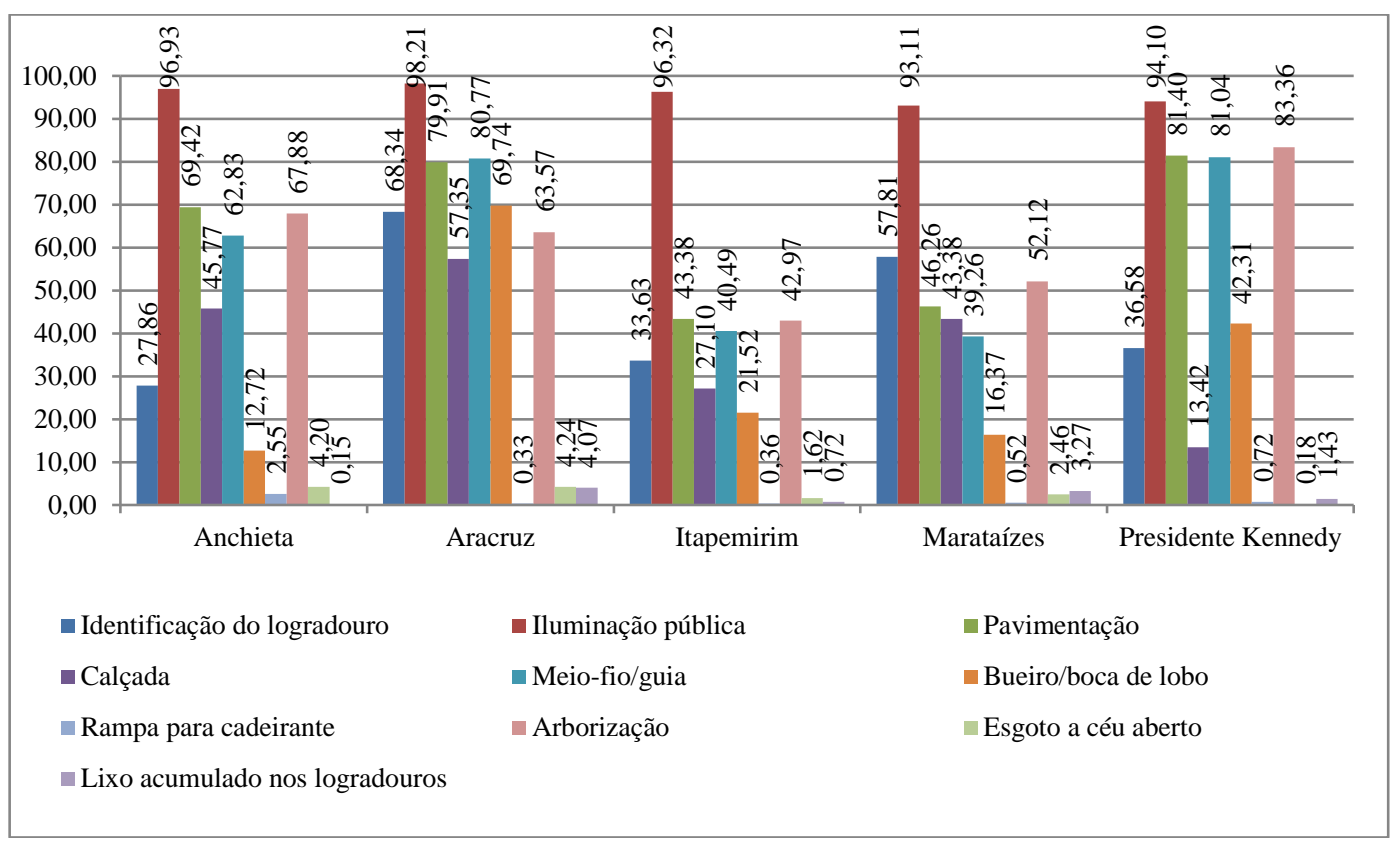

Fonte: IBGE (2010). 
Nota: Em Anchieta, foram 5.480 domicílios que declararam estas informações; em Aracruz, 20.906 declarantes; em Itapemirim, 5.539 declarantes; em Marataízes, 8.139 declarantes; e, em Presidente Kennedy, 1.118 declarantes.

Já como forma de avaliar a "construção das cidades", tem-se nas Tabelas $5 \mathrm{e}$ 6, e nos Gráficos 5 e 6, dados sobre as quantidades de empregos e de estabelecimentos formais na construção civil, entre 2002 e 2016. Com base nesta análise, percebe-se que Aracruz teve a maior quantidade de empregos formais no setor, durante quase todo o período avaliado (exceto em 2013), e de estabelecimento, em toda série histórica.

Ao avaliar as participações percentuais dos empregados e dos estabelecimentos formais da construção civil, no total do município de Aracruz, observa-se que os mesmos tiveram uma tendência de crescimento, entre 2011 e 2015, que por sua vez, é quando se inicia a construção do Estaleiro Jurong e se entrega o primeiro navio, respectivamente. Entre os anos de 2002 e 2016, em Aracruz, também se constata um aumento no número de empregos formais no setor.

Além disso, em Anchieta, verifica-se que o número de empregos no setor da construção civil, oscilou conforme o período da implantação da terceira e da quarta usinas de pelotização, como indicado pela empresa (SAMARCO, 2014).

Já em Itapemirim, Marataízes e Presidente Kennedy, percebe-se o reduzido número de empregos formais no setor, quando se comparado aos demais casos de Anchieta e Aracruz. Porém, em Itapemirim e Marataízes, destacam-se os crescimentos nas quantidades de empregos formais, entre os anos de 2002 e 2016.

Tabela 5. Quantidade de empregos formais na construção civil nos municípios, entre 2002-2016

\begin{tabular}{crrrrr}
\hline Município & \multicolumn{1}{c}{ Anchieta } & \multicolumn{1}{c}{ Aracruz } & Itapemirim & Marataízes & Presidente Kennedy \\
\hline 2002 & 195 & 963 & 10 & 5 & 17 \\
2003 & 150 & 988 & 6 & 10 & 4 \\
2004 & 149 & 887 & 25 & 27 & 1 \\
2005 & 340 & 613 & 18 & 79 & 9 \\
2006 & 690 & 1.192 & 69 & 113 & 23 \\
2007 & 583 & 1.787 & 18 & 73 & 8 \\
2008 & 264 & 1.975 & 25 & 93 & 24 \\
2009 & 292 & 4.606 & 25 & 94 & 15 \\
2010 & 301 & 5.170 & 42 & 127 & 13 \\
2011 & 949 & 4.064 & 57 & 93 & 31 \\
2012 & 2.625 & 2.878 & 52 & 100 & 2 \\
2013 & 2.299 & 2.190 & 77 & 139 & 7 \\
2014 & 607 & 3.425 & 99 & 134 & 19 \\
2015 & 457 & 2.460 & 133 & 130 & 54 \\
2016 & 233 & 2.411 & 106 & 113 & 19 \\
\hline
\end{tabular}

Fonte: Ministério do Trabalho (2002-2016) 
Gráfico 8. Participação percentual dos empregos formais da construção civil no total

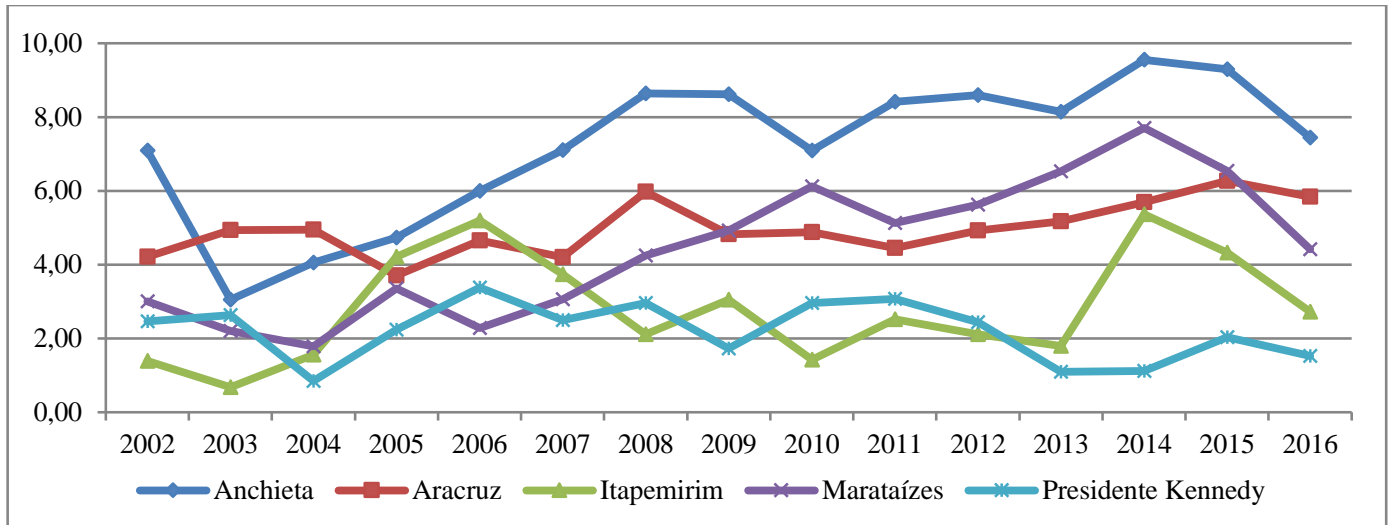

Fonte: Ministério do Trabalho (2002-2016)

Tabela 6. Quantidade de estabelecimentos formais na construção civil nos municípios, entre 2002-2016

\begin{tabular}{crrrrr}
\hline Município & Anchieta & \multicolumn{1}{c}{ Aracruz } & Itapemirim & Marataízes & Presidente Kennedy \\
\hline 2002 & 21 & 50 & 4 & 10 & 3 \\
2003 & 9 & 63 & 2 & 8 & 3 \\
2004 & 12 & 67 & 5 & 6 & 1 \\
2005 & 15 & 52 & 14 & 11 & 3 \\
2006 & 21 & 69 & 19 & 8 & 5 \\
2007 & 27 & 67 & 14 & 11 & 4 \\
2008 & 38 & 100 & 8 & 15 & 5 \\
2009 & 40 & 82 & 13 & 22 & 3 \\
2010 & 33 & 86 & 6 & 29 & 5 \\
2011 & 43 & 81 & 12 & 26 & 6 \\
2012 & 46 & 91 & 10 & 28 & 5 \\
2013 & 44 & 101 & 9 & 39 & 2 \\
2014 & 53 & 116 & 28 & 47 & 2 \\
2015 & 54 & 128 & 23 & 40 & 3 \\
2016 & 42 & 117 & 15 & 27 & 3 \\
\hline
\end{tabular}

Fonte: Ministério do Trabalho (2002-2016) 
Gráfico 9. Participação percentual dos estabelecimentos formais da construção civil no total

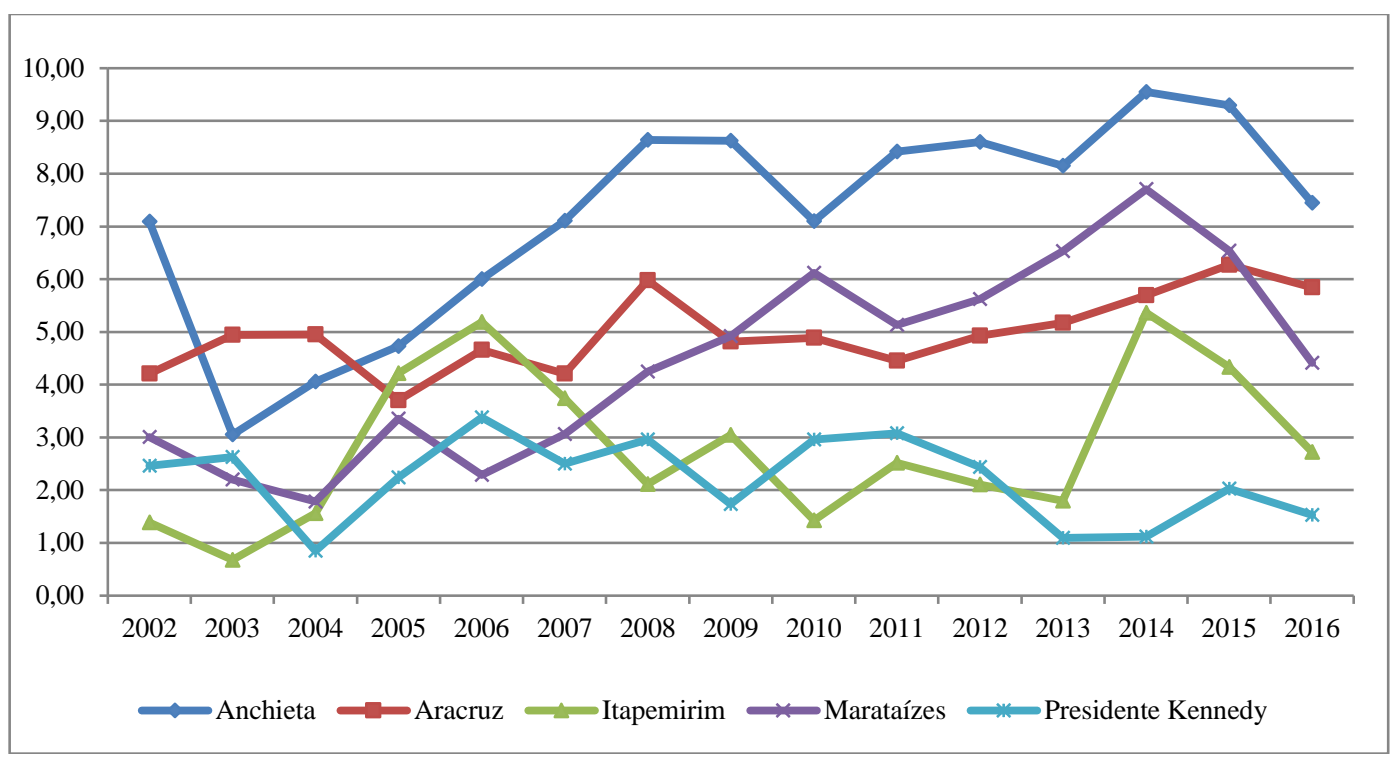

Fonte: Ministério do Trabalho (2002-2016).

Cabe destacar ainda que em todos os cinco municípios, ocorreu uma queda na participação percentual de empregos e de estabelecimentos do setor da construção civil, no total, entre os anos de 2015 e 2016. Neste caso, destaca-se os dados de Anchieta, uma vez que a Samarco não operou durante o ano de 2016, devido o acidente em Mariana (MG).

Diante desta análise em conjunto, ou seja, do número de empregos e de estabelecimentos formais no setor, é possível supor que suas atividades estão muito mais associadas aos grandes empreendimentos, do que efetivamente a ampliação e a melhoria das cidades, especialmente em Anchieta, Itapemirim, Marataízes e Presidente Kennedy. Tal afirmação pode ser concluída, tendo em vista as diferenças entre as respectivas quantidades (de empregos e de estabelecimentos formais no setor), e os próprios desempenhos nos indicadores urbanísticos (conforme Tabelas 3 e 4, e Gráfico 4).

\section{CONCLUSÃO}

Por meio das análises realizadas e, mesmo da história entre a relação dos empreendimentos e as cidades, nota-se que, pelo menos nos cinco casos avaliados, a citação sobre "as grandes empresas" terem sido as responsáveis por fazerem as cidades, como citado por Arantes (2002), de fato parece equivocada.

Tal fato se deve porque, mesmo com a presença de grandes empreendimentos e com um excelente desempenho econômico (já que possuem os maiores PIBs per capitas do Estado), os mesmos não se traduziram em melhorias plenas para as cidades, tendo em vista a existência de domicílios sem água encanada, sem coleta de lixo ou sem energia, conforme levantamentos realizados pelo Censo Demográfico de 2010. Além disso, Aracruz que possui um grande empreendimento industrial desde os anos 1970 , tem no entorno de mais de $4 \%$ de seus domicílios, "esgoto a céu aberto" e "lixo acumulado nos logradouros". 
Todavia, cabe reconhecer as transformações nas cidades em questão, desencadeadas pelos processos de industrialização, especialmente em Aracruz, apesar de não terem tido melhorias plenas na cidade, como foi evidenciado.

Em Anchieta, mesmo com um grande empreendimento industrial, resultado da captação de recursos durante a implantação do II PND, na década de 1970, e um dos maiores PIBs per capita do Estado atualmente, também se percebe alguns problemas gerais nas características da cidade.

Já os demais municípios do Sul do Espírito Santo (Itapemirim, Marataízes e Presidente Kennedy), por seus investimentos no setor petrolífero serem muito recentes, cujo destaque ocorreu principalmente a partir das descobertas do Pré-sal, em 2007, observa-se algumas mudanças nas cidades, a partir do aumento na quantidade de empregos formais na construção civil, especialmente em Itapemirim e Marataízes. Contudo, assim como nos demais casos, este desempenho parece estar mais atrelado as atividades econômicas em geral, do que a própria estruturação das cidades.

Outra questão que demonstra a relação dos grandes empreendimentos com as cidades, é que ao analisar a quantidade de empregos e de estabelecimentos formais da construção civil, mesmo precisando de um maior detalhamento para esta conclusão, tem-se que as oscilações no setor ocorreram no mesmo momento em que se tem grandes investimentos, como nos casos da Samarco, em Anchieta, e do Jurong, em Aracruz.

Além disso, vale citar que nenhum dos cinco municípios analisados, possuem sedes administrativas dos empreendimentos mencionados atualmente, apesar da Aracruz Celulose ter permanecido em Aracruz até 2009 (ou seja, até a constituição da Fibria - hoje, Suzano).

\section{REFERÊNCIAS BIBLIOGRÁFICAS}

AEQUUS CONSULTORIA. Finanças dos municípios capixabas. 2004, 2007, 2010, 2013, 2016, 2017. Disponível em: <http://www.aequus.com.br/>. Acesso em 20 out. 2017.

AGÊNCIA NACIONAL DE TRANSPORTES AQUAVIÁRIOS - ANTAQ. Instalações portuárias - portos brasileiros: Barra do Riacho. Disponível em: <http://observatorioantaq.info/>. Acesso em 20 out. 2017.

AGÊNCIA NACIONAL DO PETRÓLEO, GÁS NATURAL E BIOCOMBUSTÍVEIS ANP. Dados estatísticos. Disponível em: <http://www.anp.gov.br/>. Acesso em 15 nov. 2017.

ARANTES, O. Uma estratégia fatal: A cultura nas novas gestões urbanas. In: ARANTES, O.; VAINER, C.; MARICATO, E. A cidade do pensamento único: desmanchando consensos. Petrópolis-RJ: Editora Vozes, 2002. p. 11-74.

BARROS, R. M. Presidente Kennedy continua com maior PIB per capita do país. Gazetaonline. 14 dez. 2017. Disponível em: <http://www.gazetaonline.com.br/>. Acesso em 14 dez. 2017.

BITENCOURT, C.P. Empreendimentos costeiros de grande porte e conflitos no uso e ocupação do solo: a zona costeira sul capixaba. 2013. 304 p. Dissertação 
(Mestrado em Arquitetura e Urbanismo) - Programa de Pós-Graduação em Arquitetura e Urbanismo, Universidade Federal do Espírito Santo, Vitória/ES, 2013.

BITTENCOURT, G. A formação econômica do Espírito Santo: o roteiro da industrialização. Rio de Janeiro: Editora Cátedra, 1987. 302 p.

ESPÍRITO SANTO. Lei Estadual no 9.768, de 28 de dezembro de 2011. Dispõe sobre a definição das Microrregiões e Macrorregiões de Planejamento no Estado do Espírito Santo. Disponível em: <http://www.al.es.gov.br/>. Acesso em 10 out. 2017.

ESTALEIRO JURONG ARACRUZ - EJA. Institucional. Disponível em: <http://www.jurong.com.br/>. Acesso em 25 out. 2017.

FERREIRA, G.A.C. A lei no plano e o plano na lei: Convergências, divergências e silêncios na constituição do território corporativo capixaba. 2016. 557 p. Tese (Doutorado em Arquitetura e Urbanismo) - Faculdade de Arquitetura, Universidade Federal Fluminense, Niterói/RJ, 2016.

FERREIRA, J.S.W. A cidade para poucos: breve histórico da propriedade urbana no Brasil. Publicado em anais do Simpósio "Interfaces das representações urbanas em tempos de globalização", UNESP Bauru e SESC Bauru, 21 a 26 de agosto de 2005. Disponível em: <http://www.fau.usp.br/>. Acesso em 07 out. 2017.

FERREIRA, J.S.W. Globalização, ideologia e planejamento urbano. In: FERREIRA, J.S.W. O mito da cidade-global: o papel da ideologia na produção do espaço urbano. Petrópolis: Vozes, 2007.

FIBRIA. Institucional. Disponível em: <http://www.fibria.com.br/>. Acesso em 01 nov. 2017.

FOLHA VITORIA. Investimentos devem gerar $\mathbf{5 0}$ mil empregos no Espírito Santo até 2014. 21 nov. 2010. Disponível em: <http://www.folhavitoria.com.br/>. Acesso em 01 nov. 2017.

GONTIJO, M.L.; PIMENTEL, T. Samarco retoma extração de minério em Mariana no ano em que tragédia com 19 mortos completou 5 anos. G1. 23 dez. 2020. Disponível em: $\quad<h$ ttps://g1.globo.com/mg/minas-gerais/noticia/2020/12/23/a-mineradorasamarco-retoma-atividades-em-mariana-no-ano-que-completou-5-anos-da-tragediaque-matou-19-pessoas.ghtml>. Acesso em 25 jan. 2021.

INSTITUTO BRASILEIRO DE GEOGRAFIA E ESTATÍSTICA - IBGE. Censo Demográfico. 1940-2010. Disponível em: <www.ibge.gov.br>. Acesso em 25 out. 2017.

Estimativas de população para 1ำ de julho de 2016. Disponível em: <www.ibge.gov.br>. Acesso em 25 out. 2017. out. 2017.

IBGE Cidades. Disponível em: <https://cidades.ibge.gov.br/>. Acesso em 25 
INSTITUTO ESTADUAL DE MEIO AMBIENTE E RECURSOS HÍDRICOS - IEMA. Samarco Mineração S/A: RIMA - Relatório de Impacto Ambiental do Projeto da $4^{\circ}$ Usina de Pelotização em Ponta de Ubu, ES. Relatório Técnico Final. CPM RT 409/09. Disponível em: <https://iema.es.gov.br/>. Acesso em 20 out. 2017.

INSTITUTO DE PESQUISA ECONÔMICA APLICADA - IPEA. Ipeadata. Disponível em: <http://www.ipeadata.gov.br/>. Acesso em 15 dez. 2017.

INSTITUTO JONES DOS SANTOS NEVES - IJSN. Mapas. 2011. Disponível em: <http://www.ijsn.es.gov.br/>. Acesso em 25 out. 2017.

Produto Interno Bruto Municipal. 2002 a 2015. Disponível em: <http://www.jjsn.es.gov.br/>. Acesso em 15 dez. 2017.

MINISTÉRIO DO TRABALHO - MTb. Relação Anual de Informações Sociais RAIS. Disponível em: <http://pdet.mte.gov.br/>. Acesso em 25 out. 2017.

NOBRE, E. A. C. Expansão terciária e nova centralidades nas cidades globais: o caso da marginal do rio Pinheiros em São Paulo. In: ENCONTRO NACIONAL DA ASSOCIAÇÃO NACIONAL DE PESQUISA E PÓS-GRADUAÇÃO EM PLANEJAMENTO URBANO E REGIONAL - ENANPUR, 9, 2001, Rio de Janeiro. Ética, planejamento e construção democrática do espaço. Anais do IX Encontro Nacional da ANPUR. Rio de Janeiro: ANPUR, 2001. v. 1, 519-527.

PEREIRA, G. H. Política industrial e localização de investimentos e o caso do Espírito Santo. Vitória-ES: Edufes, 1997.

PETROBRAS. Novos Empreendimentos de Gás no ES. 07 out. 2010. Disponível em: <http://www.investidorpetrobras.com.br/>. Acesso em 20 out. 2017.

PROGRAMA DAS NAÇÕES UNIDAS PARA O DESENVOLVIMENTO - PNUD. Atlas de Desenvolvimento Humano no Brasil. 2013. Disponível em: <http://www.atlasbrasil.org.br/2013/>. Acesso em 05 out. 2017.

RIBEIRO, F.A. FINDES 50 anos: a história da Federação das Indústrias do Estado do Espírito Santo. Vitória: FINDES, 2010, 258 p.

ROCETTI, J.P.; SEIXAS, B. Vídeo mostra como é por dentro uma plataforma de petróleo no ES. Gazetaonline. 27 set. 2017. Disponível em: <https://www.gazetaonline.com.br/>. Acesso em 25 nov. 2017.

ROCHA, H. C.; MORANDI, A. M. Cafeicultura e grande indústria: a transição no Espírito Santo - 1955-1985. 2ª edição. Vitória-ES: Espírito Santo em Ação, 2012. 173 p.

SAMARCO. Entenda o rompimento. 2017. Disponível em: <http://www.samarco.com/rompimento-de-fundao/>. Acesso em 25 out. 2017.

Relatório de Sustentabilidade. 2014. Disponível em: $\overline{<h t t p: / / w w w . s a m a r c o . c o m />. ~ A c e s s o ~ e m ~} 25$ out. 2017. 
SUZANO. A companhia: histórico. Disponível em: <https://ri.suzano.com.br/Portuguese/a-companhia/historico/default.aspx>. Acesso em 25 jan. 2021.

VETTORAZZO, L. Municípios produtores de petróleo e mineração caem em ranking do PIB. Folha de São Paulo. 14 dez. 2017. Disponível em: <http://www1.folha.uol.com.br/>. Acesso em 14 dez. 2017. 